
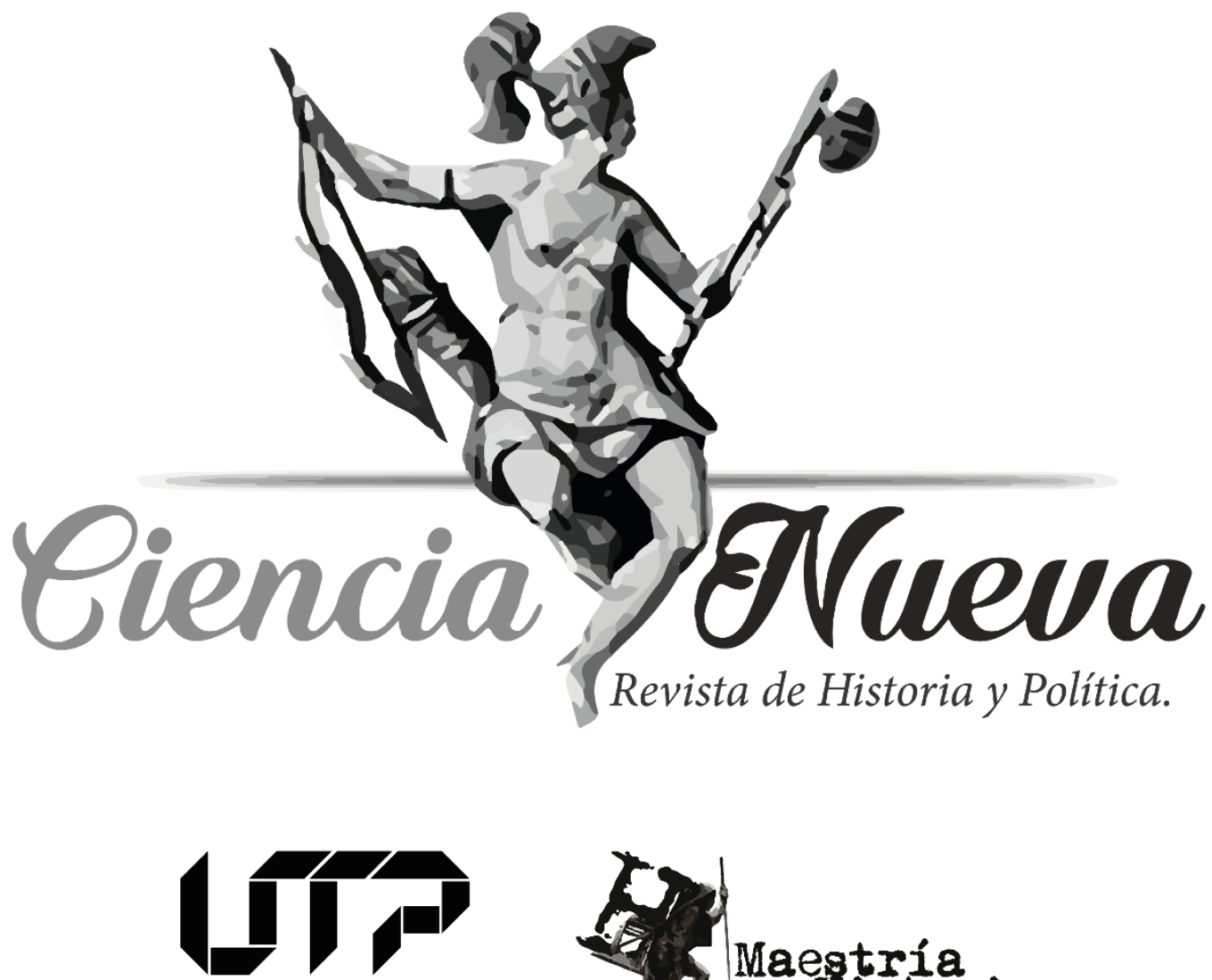

Universidad Tecnológica de Pereira

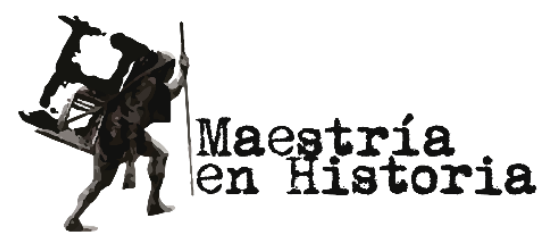

CIENCIAS POLÍTICAS

EL MAPA POLÍTICO SURAMERICANO: ALGUNOS DEBATES Y LECTURAS SOBRE SUS RECONFIGURACIONES RECIENTES

THE SOUTH AMERICAN POLITICAL MAP: SOME DEBATES AND LECTURES ABOUT ITS RECENT RECONFIGURATIONS María Virginia Quiroga pp. 83-102

Vol. 4 Núm. 1 | Enero-Junio de 2020 Pereira, Colombia 


\title{
EL MAPA POLÍTICO SURAMERICANO: ALGUNOS DEBATES Y LECTURAS SOBRE SUS RECONFIGURACIONES RECIENTES*
}

\author{
THE SOUTH AMERICAN POLITICAL MAP: \\ SOME DEBATES AND LECTURES ABOUT ITS RECENT RECONFIGURATIONS
}

María Virginia Quiroga** mvqui@hotmail.com

ORCID: http://orcid.org/0000-0002-1125-9283

\begin{tabular}{cl}
\hline Recibido: & 06 de mayo de 2019. \\
Revisado: & 25 de septiembre de 2019. \\
Aceptado: & 16 de mayo de 2020. \\
Publicado: & 04 de septiembre de 2020. \\
\hline
\end{tabular}

\section{Resumen}

Este artículo pretende sistematizar un conjunto de lecturas e interpretaciones que, desde el campo de las ciencias sociales, procuraron analizar el mapa político del Cono Sur latinoamericano en el transcurso de las últimas dos décadas. Para ello se emprende una revisión bibliográfica extensa, aunque no exhaustiva, de aquellos textos que se enfocaron en la caracterización y clasificación del conjunto de los gobiernos de la región, y que se inscribieron en el debate en torno a la magnitud de los cambios alcanzados.

Los inicios del siglo XXI mostraron la emergencia y consolidación de gobiernos que evidenciaron un "giro a la izquierda", al tomar distancia de los preceptos neoliberales y acercarse a la movilización popular. No obstante, en la actualidad su impronta parece haberse estancado y reducido. Desde el 2015 hasta nuestros días, ante el avance del denominado "giro a la derecha" se abren nuevos interrogantes y desafíos que resuenan fuertemente en las pesquisas analizadas.

Palabras clave: América del Sur, gobiernos, izquierda, derecha, fin de ciclo.

\begin{abstract}
This article attempts to systematize a set of researches and interpretations, coming from social sciences, which tends to analyze the South American's political map trough over the last two decades. To do this, we realize an extensive, but not exhaustive, bibliographic review. It considers those texts that focus on the characterization and classification of the collectivity of Southamerican Governments and takes part on the debates about the magnitude of the changes achieved.

The beginnings of the new century showed the emergence and consolidation of Governments which represent a "left turn", taking distance from the neoliberal precepts and making an approach with popular mobilization. Many discussions have been established about the best ways of nominating this new cycle; however, "progressive" governments seem to be losing territory and strength. In front of the "right turn" advance, from 2015 until our days, new questions and challenges have recurrently appeared on the researchers analyzed.
\end{abstract}

Key Words: South America, Governments, left, right, end of cycle.

\footnotetext{
* Este documento respeta las directrices y normas dispuestas en la Declaración de Ética de Publicación de Ciencia Nueva, Revista de Historia y Política. Esta declaración puede consultarse en la página web de la revista: http://revistas.utp.edu.co/index.php/historia

** Licenciada en Ciencia Política de la Universidad Nacional de Río Cuarto, Argentina. Doctora en Estudios Sociales de América Latina del Centro de Estudios Avanzados de la Universidad Nacional de Córdoba, Argentina. Becaria Postdoctoral del Consejo Nacional de Investigaciones Científicas y Técnicas (CONICET, Argentina). Profesora titular de la Facultad de Ciencias Humanas de la Universidad Nacional de Río Cuarto, Argentina.
} 


\section{Introducción}

comienzos del siglo XXI, el mapa político de la región suramericana mostró la
emergencia y consolidación de una gran diversidad de gobiernos de centro izquierda,
progresistas, posneoliberales o populistas. Desde el plano académico y político, se discutió mucho sobre las mejores formas de denominar a la ola de presidentes que, desde Hugo Chávez en adelante ${ }^{227}$, intentaba reparar progresivamente el tejido social, recuperar el rol protagónico del Estado en la economía y favorecer los procesos de integración latinoamericana. Se ensayaron múltiples clasificaciones al respecto, estableciendo distinciones sociológicas (según la mayor o menor resonancia de los sectores populares), históricas (de acuerdo con las rupturas y continuidades con experiencias y tradiciones precedentes), politológicas (en relación con la dinámica del sistema de partidos y los vínculos con los procesos de democratización) y económicas (sopesando los alcances y límites del modelo de acumulación, y el distanciamiento respecto del neoliberalismo).

Mientras el debate anterior no logró saldarse, el mapa de la región volvió a reconfigurarse. Desde el 2015, la expansión territorial de los proyectos del "giro a la izquierda" se ha estancado y reducido. Han ido cobrando centralidad los sectores sociales y coaliciones gubernamentales críticas de la agenda nacional-popular que había hegemonizado el escenario político de la década previa. En ese marco, emergieron gobiernos con perfil empresarial/tecnocrático ${ }^{228}$ que optaron por gestionar lo público con lógicas del sector privado, armando gabinetes con funcionarios del mundo de los negocios y privilegiando medidas de corte regresivo.

El devenir de los procesos en curso ha suscitado el desarrollo de diversas producciones teóricas y estudios de casos que buscan comprender el paso desde un "giro a la izquierda", a comienzos del siglo XXI, hacia un reciente "giro a la derecha". Algunos trabajos privilegiaron las virtudes de las nuevas gestiones, mientras que otros enfatizaron los desaciertos de los gobiernos progresistas. Para algunos analistas, durante la primera década del siglo, se lesionaron intereses de factores decisivos de poder; entretanto, para otros, el problema radicó en dejar intactos esos intereses, que hoy recobrarían mayor protagonismo. Al mismo tiempo, vastas investigaciones reactualizaron discusiones sobre el binomio izquierda-derecha, y se preguntaron por las posibilidades de los nuevos gobiernos para consolidar su hegemonía.

En definitiva, el presente artículo propone una sistematización - extensa, aunque no exhaustiva - del heterogéneo conjunto de producciones dedicadas a analizar los virajes políticos de América del Sur en el lapso temporal 2002-2018. Con ese objetivo se realizó una revisión bibliográfica de las investigaciones sobre el tema. Se consideró, en primer lugar, que

\footnotetext{
${ }^{227}$ Se hace alusión a la ola de gobiernos que se inaugura con la elección de Hugo Chávez en Venezuela (1998), y las posteriores asunciones de "Lula" Da Silva en Brasil (2003), Néstor Kirchner en Argentina (2003), Tabaré Vázquez en Uruguay (2005), Michelle Bachelet en Chile (2006), Evo Morales en Bolivia (2006), Rafael Correa en Ecuador (2007) y Fernando Lugo en Paraguay (2008). A este abanico se sumarán, producto del recambio presidencial, Dilma Rousseff en Brasil, Cristina Fernández en Argentina, José Mujica en Uruguay, y Nicolás Maduro en Venezuela. También suele considerarse a Ollanta Humala (2011) en Perú como parte de esta oleada. ${ }^{228}$ En este otro grupo entrarían las presidencias de Horacio Cartes (2013-2018) y Mario Abdo Benítez (20182022) en Paraguay; Mauricio Macri en Argentina (2015-2019); Pedro Pablo Kuczynski en Perú (2016-2018) y su reemplazo por el primer vicepresidente Martín Vizcarra (2018-2021); Michel Temer (2016-2018) y Jair Bolsonaro (2019-2022) en Brasil; Sebastián Piñera en Chile (2018-2022), e Iván Duque en Colombia (20182022). Yamandu Acosta, Verónica Giordano y Lorena Soler, "América Latina: nuestra", Cuadernos del Pensamiento Crítico Latinoamericano 36 (2016). Verónica Giordano. "¿Qué hay de nuevo en las «nuevas derechas»?". Nueva Sociedad 254 (2014).
} 
hubieran sido publicadas en el periodo de estudio y que se inscriban en el campo de las ciencias sociales, en general, y de la ciencia política, en particular. Al mismo tiempo, en la selección del corpus se privilegiaron aquellos trabajos que intentaron caracterizar o clasificar la diversidad de gobiernos de la región (es decir, sin abocarse exclusivamente al análisis de caso). Por último, se tuvo en cuenta que de algún modo respondieran a polémicas o preguntas clave, por ejemplo: ¿Es preciso hablar de un "giro a la izquierda" y, en todo caso, de qué izquierda se habla? ¿Qué aspectos han variado en la coyuntura actual y cuáles se mantienen? ¿Estamos ante un fin de ciclo progresista o un repliegue parcial? ¿Es válida la referencia al retorno de la derecha o se trata de una nueva derecha?

En cuanto a la organización del escrito, en primer lugar, se repasan brevemente algunas caracterizaciones y balances sobre los gobiernos del "giro a la izquierda"; en segundo lugar, se presentan algunos rasgos que han sido atribuidos a las actuales gestiones "de derechas", sopesando sus rupturas, tensiones y continuidades con la década previa. Sin ánimos de formular aseveraciones cerradas, la reconstrucción de este estado de la cuestión permitirá acercarnos a la comprensión de los proyectos políticos en pugna en nuestra región, teniendo en cuenta, tanto sus heterogeneidades, como los profundos debates que suscitan.

\section{El giro a la izquierda, de la consolidación al retraimiento}

Cuando Hugo Chávez asumió el gobierno de Venezuela, en 1999, se inauguró un proceso de cambio social desde la gestión estatal, que tomaría al poco tiempo una dimensión regional. El advenimiento de este nuevo ciclo en América del Sur resultaba deudor de un acumulado de movilizaciones, protestas y diversas expresiones de acción colectiva que resistieron la embestida neoliberal de los años noventa, buscando menguar sus consecuencias a través del diseño de alternativas de supervivencia y recomposición. De este modo, se organizaron grandes manifestaciones, marchas y cortes de caminos; se implementaron ollas populares y redes del trueque; se recuperaron fábricas y cooperativas de trabajo; se debatió en asambleas populares y ampliados, y en definitiva se repensaron los modos de vinculación entre la sociedad y la política.

Entonces, el cambio de siglo mostró la expansión de un abanico de gobiernos vinculados — en mayor o menor medida - con los crecientes procesos de movilización social. Estos impulsaron políticas que pretendían ampliar el rol del Estado y favorecer la participación en la toma de decisión pública. En esa línea, el Estado asumió protagonismo en el control, generación y utilización de los excedentes ${ }^{229}$. Además, desempeñó un nuevo rol como agente organizador de la política social, que buscó expandir el alcance de los programas sociales $^{230}$ desde un enfoque de derechos. Más allá de un recuento acabado, interesa destacar que estas medidas (en un contexto internacional de alza de los precios de las materias primas) arrojaron resultados socioeconómicos positivos, y se forjaron al calor de la apertura de la gestión estatal a diversas organizaciones y sectores movilizados.

Las apreciaciones precedentes despertaron cierto consenso inicial en la literatura sobre el tema. En tanto diversas investigaciones coincidieron en que, más allá de sus diferencias y coyunturas particulares, los gobiernos del nuevo ciclo intentaron reparar progresivamente el

\footnotetext{
229 Vale citar medidas como la nacionalización de los hidrocarburos (Venezuela, Bolivia, Ecuador), la recuperación de empresas estratégicas (a lo que se sumarían Argentina y Brasil); también el mayor control sobre los aranceles aduaneros, el fomento a la industria y al desarrollo de grandes proyectos energéticos.

${ }^{230}$ Destacan entre tantos otros programas, la Asignación Universal por Hijo en Argentina, la ejecución de las "misiones" en Venezuela, la mejora en el Bono de Desarrollo Humano en Ecuador, el Programa Bolsa Familia en Brasil, el Bono Juancito Pinto y Juana Azurduy en Bolivia, entre otros.
} 
tejido social, recuperar la soberanía nacional y favorecer la integración regional. No obstante, la valoración de la magnitud de los cambios operados suscitó profundas diferencias. Es así como proliferaron diversas conceptualizaciones o caracterizaciones al respecto: nuevas izquierdas (o centro-izquierdas) en el poder, gobiernos progresistas, posneoliberales o antineoliberales, rupturas populistas, reconfiguraciones del bloque hegemónico e, incluso, revoluciones pasivas.

Unas y otras lecturas se encargaron de enfatizar el cambio del clima político e ideológico en la región, marcado fundamentalmente por el rechazo al "Consenso de Washington" 231 . Al tiempo que se preocuparon por introducir matices con relación a la historia y las configuraciones específicas de cada país. Quienes hablaron de izquierda a secas intentaron subrayar el cambio de rumbo y sopesar las vinculaciones con tradiciones precedentes, quizás teniendo en mente la clásica distinción de Norberto Bobbio ${ }^{232}$. Aquellos que aludieron al posneoliberalismo, manifestaron buscar categorías más aggiornadas a nuestro contexto espaciotemporal. Destacaron las rupturas con el modelo neoliberal a partir de la intervención del Estado en la economía, la recuperación del control de sectores estratégicos y las políticas de redistribución de ingresos. No obstante, hubo respuestas variadas por la magnitud de los cuestionamientos al sistema capitalista existente ${ }^{233}$. De este último elemento hicieron eco algunos de los enfoques que privilegiaron el mote de progresismo, pretendiendo encontrar un concepto que vinculara realidades diferentes y diera cuenta del impulso de numerosas transformaciones, sin que ello implicara cambios estructurales $^{234}$. Es más, llegó a caracterizarse al ciclo progresista latinoamericano como un conjunto de diversas versiones de revolución pasiva — apelando al término gramsciano-,

${ }^{231}$ Se refiere al conjunto de medidas de política económica indicadas o "recetadas" por los organismos multilaterales de crédito (Fondo Monetario Internacional y Banco Mundial, fundamentalmente) para aplicar en la región latinoamericana hacia fines de los años ochenta. La expresión propiamente dicha fue acuñada por el economista británico John Williamson en un artículo publicado en 1989. Se refería al consenso -con epicentro en la ciudad de Washington - sobre la necesidad de aplicar reformas macroeconómicas (disciplinamiento fiscal, racionalización del gasto público, liberalización financiera), reformas del comercio exterior (liberalización de importaciones, eliminación de subsidios, bajas aduaneras) y el fomento del sector privado.

${ }^{232}$ Para el autor italiano, derecha e izquierda constituyen conceptos antitéticos; mientras la primera enaltece la igualdad, la segunda toma a la libertad individual como valor supremo. Norberto Bobbio, Derecha e izquierda, razones y significados de una distinción política (Madrid: Gráfica Internacional, 1997). Jorge Castañeda, "Latin America's Left Turn", Foreign Affairs 85, n. 3 (2006). Manuel Alcántara, "La escalada de la izquierda. La ubicación ideológica de presidentes y partidos de izquierda en América Latina”, Nueva Sociedad 217 (2008). Steven Levitsky y Kenneth Roberts, eds, The Resurgence of the Latin American Left (Baltimore: The Johns Hopkins University Press, 2011). Susan Stokes, Globalization and the Left in Latin America (Yale University, 2009), acceso el 15 de junio de http://citeseerx.ist.psu.edu/viewdoc/download?doi=10.1.1.464.4640\&rep=rep1\&type=pdf

${ }^{233}$ Franciso López, América Latina: crisis del posneoliberalismo y ascenso de la nueva derecha (Buenos Aires: CLASCO, 2016). Franklin Ramírez, "'Posneoliberalismo' y 'neodesarrollismo': ¿Las nuevas coordenadas de acción política de la izquierda latinoamericana?", Revista La Tendencia 5 (2007). Cristobal Rovira, "Toward post-neoliberalism in Latin America", Latin American Research Review 46, n. 2 (2011). Emirs Sader, Posneoliberalismo en América Latina (Buenos Aires: ClaCso, 2008).

234 Massimo Modonesi, "Revoluciones pasivas en América Latina. Una aproximación gramsciana a la caracterización de los gobiernos progresistas de inicio de siglo", en Horizontes gramscianos. Estudios en torno al pensamiento de Antonio Gramsci, comp. por Massimo Modonesi (México: UNAM, 2013), 209-236. Maristella Svampa, Cambio de Época. Movimientos sociales y poder político (Buenos Aires: Siglo Veintiuno Editores, 2008). Raul Zibechi, Política y Miseria (Buenos Aires: La Vaca, 2010). Vale aclarar que la expresión de "gobiernos progresistas" también ha contado con amplia difusión por parte de algunos de los protagonistas de los procesos políticos entonces en curso, como Rafael Correa y Álvaro García Linera, quienes resaltaron el cambio de época a partir de la recuperación de las capacidades estatales al servicio de las mayorías populares. 
en tanto las transformaciones se impulsaban desde arriba y por medio de prácticas políticas desmovilizadoras y subalternizantes ${ }^{235}$.

La categoría de populismo suscita un debate aparte por la diversidad de aristas que engloba y por su vinculación con discusiones precedentes ${ }^{236}$. Para este trabajo, vale la pena señalar que algunos analistas identificaron el populismo de los nuevos gobiernos en su propuesta de recomposición ante la crisis hegemónica del neoliberalismo, con privilegio de los sectores antes marginados ${ }^{237}$; mientras que otros autores hicieron hincapié en el liderazgo carismático/demagógico y la centralización del poder en torno a los presidentes electos ${ }^{238}$.

Desde el primer punto de vista, estas experiencias ponían de relieve una lógica de tipo populista, al provocar una ruptura con el statu quo imperante y proponer alternativas de recomposición basadas en la construcción de una identidad popular ${ }^{239}$. Ello, a su vez, conllevaba a la dicotomización del espacio social entre el bloque de poder y el pueblo ${ }^{240}$, donde este último se constituía a partir de interpelar a los sectores relegados, a "aquellos que no estaban incorporados a lo común de la comunidad"241.

En cuanto al segundo sentido, destaca la posición que Maristella Svampa explicita en sus dos últimos trabajos ${ }^{242}$. Para la autora los gobiernos del "cambio de época"243 constituyen "populismos de alta intensidad" o "populismos en sentido fuerte", ya que buscan contener los procesos genuinos de movilización social. Esto es, el accionar autónomo "desde abajo". Justamente en un artículo conjunto con Massimo Modonesi, los investigadores advierten que el progresismo latinoamericano fue adoptando cada vez más un formato populista. Evidente en la construcción de un determinado tipo de hegemonía a través de la oposición y al mismo tiempo "de la absorción y la negación de elementos propios de otras matrices

${ }^{235}$ Modonesi, "Revoluciones pasivas en América Latina. Una aproximación gramsciana a la caracterización de los gobiernos progresistas de inicio de siglo".

${ }^{236}$ No es objeto de este trabajo adentrarse in extenso en el debate en torno al populismo, para una empresa semejante pueden consultarse trabajos previos de la autora: María Virginia Quiroga, "Debates y recepciones de la perspectiva laclausiana del populismo. Pueblo e instituciones en los discursos populistas latinoamericanos", POSTData, Revista de Reflexión y Análisis Político 19, n. 2 (2014): 377-394. María Virginia Quiroga y Ana Lucía Magrini, "La constitución de un concepto iterativo en América Latina. Tensiones y polémicas en torno al populismo", Revista Fundamentos en Humanidades, año XV, n. ${ }^{\circ}$ II (2014): 27-40.

${ }^{237}$ Roberto Follari, La alternativa neopopulista, el reto latinoamericano al republicanismo liberal (Rosario: Homo Sapiens, 2010). Ernesto Laclau, "La deriva populista y la centroizquierda latinoamericana", Nueva Sociedad 205 (2006): 56-61. Martín Retamozo, "Democracias y populismos en América del Sur: Otra perspectiva. Un comentario a «La democracia en América Latina: la alternativa entre populismo y democracia deliberativa» de Osvaldo Guariglia", ISEGORÍA. Revista de Filosofía Moral y Política 47 (2012): 615-632.

${ }^{238}$ Carlos de la Torre, "El populismo latinoamericano, entre la democratización y el autoritarismo". Nueva Sociedad (2013) 247: 2-17. Jorge Lanzaro, La tercera ola de las izquierdas latinoamericanas: entre el populismo y la social-democracia (Montevideo: Instituto de Ciencia Política, Universidad de la República, 2007). Ludolfo Paramio, "Giro a la izquierda y regreso del populismo", Nueva Sociedad 205 (2006): 62-74.

${ }^{239}$ Benjamín Arditti, “El giro a la izquierda en América Latina. ¿Una política post-liberal?”, Latin American Research Review 43, n 3 (2008): 59-81. Fracisco Panizza, "Fisuras entre Populismo y Democracia", Stockholm Review of Latin American Sutidies, n. ${ }^{\circ} 3$ (2008): 81-93.

${ }^{240}$ Laclau, "La deriva populista y la centroizquierda latinoamericana".

${ }^{241}$ Sebastián Barros, "Espectralidad e inestabilidad institucional. Acerca de la ruptura populista" (ponencia presentada en el VII Congreso Nacional de Ciencia Política, de la Sociedad Argentina de Análisis Político, Córdoba, 2005, 7).

${ }^{242}$ Maristella Svampa, Debates latinoamericanos. Indianismo, desarrollo, dependencia, populismo (Buenos Aires: Edhasa, 2016). Maristella Svampa, Del cambio de época al fin de ciclo (Buenos Aires: Edhasa, 2017).

${ }^{243}$ Se trata de una expresión del entonces presidente de Ecuador, Rafael Correa; quien en 2007 sostuvo que lo que se vivía no era una "época de cambios" sino un "cambio de época". Maristella Svampa (2008) recoge esta referencia como título de su libro. 
contestatarias" "244 que "habrían tenido un rol importante en los inicios del cambio de época" ${ }^{\prime 245}$.

Otra cuestión importante para considerar en esta sistematización es que las diversas caracterizaciones sobre el "giro a la izquierda" han ensayado clasificaciones que buscaron contemplar la diversidad del mapa regional; pero lo hicieron estableciendo criterios de demarcación bien diferentes. Hubo quienes difundieron la idea de "dos izquierdas", identificando a una de ellas como "populista radical" y a la otra como "racional y moderada" 246 . Dicha perspectiva se basó principalmente sobre indicadores como el tipo de partido o movimiento que compone la presidencia, la fisonomía de cada sistema de partidos, su magnitud competitiva y su grado de institucionalización ${ }^{247}$. Mientras tanto, aquellos que optaron por hablar de posneoliberalismo, progresismo e incluso populismo en un sentido no peyorativo, intentaron trascender la perspectiva institucionalista. En esa línea, una de las variables privilegiadas fue la articulación entre gobiernos y movimientos sociales, quizás como vara para dar cuenta del carácter y el alcance de las políticas públicas implementadas. Desde esta óptica, se marcó la radicalidad de los procesos políticos venezolano, boliviano y ecuatoriano, a partir de su rasgo constituyente ${ }^{248}$ y la centralidad otorgada a actores otrora relegados $^{249}$. Los tres casos mencionados se autodenominaron "revolucionarios": la revolución bolivariana, la revolución democrático-cultural y la revolución ciudadana, respectivamente. No obstante, también se advirtió que la radicalidad inicial de estas gestiones resultó opacada por la progresiva cerrazón del espacio político en torno a la figura del líder y el fomento de políticas de corte extractivista, sumado a las crecientes denuncias por corrupción o falta de transparencia ${ }^{250}$.

\footnotetext{
${ }^{244}$ Se refieren especialmente a la narrativa indígena-campesina, diversas izquierdas clásicas o tradicionales y las nuevas izquierdas autonómicas. Maristella Svampa, y Massimo Modonesi, "Las derivas de los progresismos realmente existentes", La Izquierda Diario, 2016. Acceso 9 de abril de 2017. https://www.laizquierdadiario.com/Las-derivas-de-los-progresismos-realmenteexistente

${ }^{245}$ Svampa y Modonesi, "Las derivas de los progresismos realmente existentes".

${ }^{246}$ Por un lado, la izquierda pragmática, sensata y moderada (Chile, Brasil, Uruguay). Por otro, la demagógica, nacionalista y populista (principalmente Venezuela, Bolivia y Ecuador). Castañeda, "Latin America's Left Turn". Frente a ello, autores como Franklin Ramírez Gallegos advirtieron que la pluralidad del mapa continental no podría encasillarse en una división binaria y se admitirían "mucho más que dos izquierdas". Franklin Ramírez, "Mucho más que dos izquierdas". Nueva Sociedad, n. 205 (2006), acceso 23 de mayo de 2016, http://nuso.org/media/articles/downloads/3379_1.pdf

247 Castañeda, "Latin America's Left Turn". Lanzaro, La tercera ola de las izquierdas latinoamericanas. Paramio, "Giro a la izquierda y regreso del populismo".

${ }^{248}$ Los textos constitucionales fueron aprobados por referéndums, comenzando en Venezuela en diciembre de 1999, más tarde en Ecuador en septiembre de 2008 y en Bolivia hacia enero de 2009. En todos los casos recibieron amplio apoyo de la población.

${ }^{249}$ Laclau, "La deriva populista y la centroizquierda latinoamericana". Panizza, "Fisuras entre Populismo y Democracia". Retamozo, "Democracias y populismos en América del Sur: Otra perspectiva. Un comentario a «La democracia en América Latina: la alternativa entre populismo y democracia deliberativa» de Osvaldo Guariglia".

${ }^{250}$ Decio Machado y Raúl Zibechi, Cambiar el mundo desde arriba. Los límites del progresismo (Bogotá: Ediciones desde abajo, 2016). Modonesi, "Revoluciones pasivas en América Latina. Una aproximación gramsciana a la caracterización de los gobiernos progresistas de inicio de siglo". Pablo Stefanoni, "Posneoliberalismo cuesta arriba. Los modelos de Venezuela, Bolivia y Ecuador en debate", Nueva Sociedad, 239 (2012a), 51-64. Svampa, Debates latinoamericanos.
} 
La gran mayoría de los trabajos citados hasta aquí se detuvieron en señalar que el contexto económico internacional había resultado favorable para el "giro a la izquierda". Principalmente por el aumento en los precios y volúmenes de las exportaciones de origen agrícola, industrias extractivas y metales. Estas producciones funcionaron como pilares del modelo de acumulación en la región y sostuvieron el aumento del ahorro nacional para la redistribución. Sin embargo, la recesión en la actividad económica global a partir de la crisis del 2008 en Estados Unidos impactó la balanza comercial suramericana. Las exportaciones se redujeron en volumen y precio, al tiempo que hubo mayores restricciones para acceder al financiamiento externo y se endurecieron las condiciones crediticias internas.

Simultáneamente, en cada país de la región fueron cobrando fuerza las demandas de diversos sectores sociales que abrían cuestionamientos a las inconsistencias del modelo económico, la falta de pluralismo y los exiguos logros para combatir la desigualdad ${ }^{251}$. Lo hacían como ciudadanos individuales, con fuerte visibilidad en los medios de comunicación o a través de sus organizaciones de base: sindicales, territoriales o socioambientales. Por su parte, los partidos políticos opositores enunciaban sus críticas con vehemencia, apelando a diversos repertorios de acción ${ }^{252}$ y pretendiendo capitalizar las nuevas demandas en pro de "seguridad", "transparencia", "pluralidad", entre otras. En ese sentido fueron ganando apoyo en algunas grandes ciudades, muchas veces capitales de los países, pero aún mostraban dificultades para alcanzar proyección nacional ${ }^{253}$.

En ese escenario comenzó a inscribirse el retraimiento o pérdida de iniciativa de los gobiernos del "giro a la izquierda". En busca de explicaciones posibles se ensayaron diversas interpretaciones desde las ciencias sociales. Los diagnósticos en juego pondrían de relieve al menos dos posturas claras: aquellas lecturas que sostuvieron la tesis del "fin del ciclo progresista" y aquellas otras que la rechazaron argumentando que se trataba de un "repliegue parcial". Dentro del primer grupo, Maristella Svampa ${ }^{254}$ afirmó que el retorno del populismo de alta intensidad y el final del ciclo de los gobiernos progresistas estaban asociados, en tanto lo primero contribuiría a explicar lo segundo. Es decir, las mismas falencias del modelo condujeron a su desenlace: la profundización de la reprimarización económica, la criminalización de la protesta, la subordinación de actores sociales y la cancelación de las

${ }^{251}$ Hans J. Burchardt, "La crisis actual de América Latina: causas y soluciones”. Nueva Sociedad 267 (2017), 114-128. Svampa, Del cambio de época al fin de ciclo...

${ }^{252}$ Inclusive, entre el abanico de repertorios de acción (marchas, concentraciones, cabildos abiertos, cortes de calles, lock outs, desabastecimientos, entre otros) destacan aquellos de carácter destituyente, como el intento de golpe de Estado cívico-prefectural en Bolivia durante septiembre de 2008 o la revuelta de las fuerzas de seguridad en Ecuador durante septiembre-octubre del 2010. Unos años después podrían sumarse las polémicas destituciones parlamentarias de los presidentes Fernando Lugo (Paraguay, 2012) y Dilma Rousseff (Brasil, 2016). Para estos dos últimos casos se recomienda revisar, respectivamente: Lorena Soler, "Golpe de Estado y derechas en Paraguay", Nueva Sociedad 254 (2014): 73-83, acceso el 5 de noviembre de 2018, http://nuso.org/media/articles/downloads/4070_1.pdf y Marcelo Braz, "O golpe nas ilusões democráticas e a ascensão do conservadorismo reacionário", Serv. Soc. 128 (2017): 85-103. http://dx.doi.org/10.1590/01016628.095 .

${ }^{253}$ Por ejemplo, en Bolivia, las elecciones de 2014 preservaron el triunfo de la oposición en alcaldías del oriente (Santa Cruz, Tarija) y también en el occidente (El Alto, La Paz, Potosí, el Cercado en Cochabamba); en Ecuador, los partidos opositores cercanos a la derecha o centro-derecha se afianzaron en Quito, Guayaquil y Cuenca; en Venezuela en la ciudad de Maracaibo y el estado de Miranda, y en Argentina, en la ciudad autónoma de Buenos Aires. Giordano, “¿Qué hay de nuevo en las «nuevas derechas»?”. Franklin Ramírez y Valeria Coronel, "La política de la «buena onda»", Nueva Sociedad 254 (2014): 136-148. Gabriel Vommaro, Sergio Morresi y Alejandro Bellotti, Mundo PRO (Buenos Aires: Planeta, 2015).

${ }^{254}$ Svampa, Debates latinoamericanos. Svampa, Del cambio de época al fin de ciclo... 
diferencias; a ello se sumaba "la caída de precios de los commodities, el fracaso del regionalismo y la dependencia con China" ${ }^{255}$. Por su parte, Massimo Modonesi también se mostró próximo a la idea del fin de ciclo, pero lo formuló como "fin de la hegemonía de los gobiernos progresistas", que se reflejaría en la "creciente incapacidad de construcción y sostenimiento del amplio consenso interclasista y de fuerte raigambre popular que caracterizó la etapa de consolidación de éstos" 256.

Prácticamente en las antípodas de esos abordajes, Álvaro García Linera ${ }^{257}$ identificó un repliegue temporal de los gobiernos progresistas, el cual permitiría capitalizar la experiencia adquirida y lanzar una "segunda oleada revolucionaria" aún más radical que la anterior. En la perspectiva del entonces vicepresidente boliviano, ello supondría la necesaria resolución de algunos límites y contradicciones ${ }^{258}$, entre los que citaba: las dificultades en la gestión económica, el descuido de la batalla cultural, la falta de una profunda reforma moral, la imposibilidad de prolongar en demasía los liderazgos políticos y la insuficiente integración económica continental. Otras voces también hicieron eco del rechazo a la tesis del fin de ciclo, pensando más bien en una restauración neoliberal a la cual la movilización social le mostraría sus límites ${ }^{259}$. En ese sentido, Atilio Borón y Frei Betto ${ }^{260}$ reconocieron que las oleadas de lucha eran interminables, a pesar de que se estaba en una fase de meseta o incluso de regresión. El devenir de los acontecimientos que se extienden más allá de nuestra etapa de estudio mostrará las vicisitudes e imbricaciones mutuas entre los ciclos políticos. Se revela, quizás, la pertinencia de categorías como la de transición para explicar aquellas situaciones en donde lo viejo se resiste a morir y lo nuevo no consigue nacer ${ }^{261}$.

\section{El giro a la derecha: entre persistencias y novedades}

La otra cara del retraimiento, pérdida de iniciativa o fin del ciclo progresista, es la expansión continental de diferentes gobiernos que reeditaron medidas de corte neoliberal y recrearon sentidos e ideas-fuerza ${ }^{262}$ volcadas hacia la derecha del espectro políticoideológico.

\footnotetext{
${ }^{255}$ Svampa, Debates latinoamericanos... 488.

${ }^{256}$ Massimo Modonesi, "Fin de la hegemonía progresista y giro regresivo en América Latina. Una contribución gramsciana al debate sobre el fin de ciclo", Viento Sur 142 (2015): 24.

257 Álvaro García, “¿Fin de ciclo progresista o proceso por oleadas revolucionarias?”, Portal digital Pulso de los pueblos, 2017, acceso el 15 de junio de 2018. http://pulsointernacional.com/fin-de-ciclo-progresista-oproceso-por-oleadas-revolucionarias-por-alvaro-garcia-linera/

${ }^{258}$ En escritos anteriores estos puntos críticos se nominaron como "tensiones creativas", ya que "tienen la potencialidad de ayudar a motorizar el curso de la propia revolución". Álvaro García, Las tensiones creativas de la revolución: quinta fase del proceso de cambio (La Paz: Vicepresidencia del Estado Plurinacional de Bolivia, 2011), 24. Luego, la expresión fue relegada y se remarcaron los cinco desafíos arriba mencionados.

${ }^{259}$ López, América Latina ... Andrés Mora, "Los límites de la restauración neoliberal”. Portal digital Pulso de los pueblos, 2017, acceso el 15 de junio de 2018, http://pulsointernacional.com/los-limites-de-la-restauracionneoliberal-por-andres-mora-ramirezl. Emir Sader, “¿Hay una nueva derecha en América Latina?”, Página 12, 24 de noviembre 2015, acceso el 7 de septiembre de 2016, https://www.pagina12.com.ar/diario/contratapa/13286779-2015-11-24.html.

${ }^{260}$ A. Borón y Frei Betto, "Es falso el fin de ciclo progresista" (conferencia en el Centro Cultural IMPA La Fábrica. Buenos Aires, 30 de mayo de 2017).

${ }^{261}$ Antonio Gramsci, Notas sobre Maquiavelo, sobre la política y sobre el Estado moderno (Buenos Aires: Nueva Visión, 1962/2003).

${ }^{262}$ Dicha noción proviene de la obra de Antonio Gramsci, Textos de los cuadernos posteriores a 1931: Antología vol. II (Buenos Aires: Siglo XXI, 1931/2014). Se emplea para dar cuenta de aquellas ideas que constituyen el motor de las fuerzas internas a una sociedad; es decir, las que funcionan como ordenadoras del mundo en un determinado tiempo-espacio y movilizan a la práctica.
} 
El mapa político actual de América Latina está en proceso de reconfiguración con gobiernos que ampliamente podríamos agrupar como de derechas. Sus fuerzas sociales y políticas ponen en circulación ideas vehiculizadas por expertos y think-tanks que dotan de sentido a la construcción del orden y construyen una comunidad de ideas ${ }^{263}$.

De este modo, el nuevo viraje fue cobrando fuerza en contraposición al "giro a la izquierda" que había comenzado a principios del siglo XXI. Vale aclarar que no se trataba de un movimiento homogéneo para la totalidad de los países de la región, pero reflejaba una tendencia general mayoritaria ${ }^{264}$ de ascenso de gobiernos que traían a escena medidas y retóricas con lineamientos claramente opuestos al ciclo progresista.

Atentos a la nueva coyuntura, diversos analistas reintrodujeron el debate sobre las derechas ${ }^{265}$, argumentando sustancialmente que estos gobiernos profundizaban los patrones de desigualdad, a través de la transferencia de ingresos hacia los capitales concentrados ${ }^{266}$. Ahora bien, mientras algunos de los autores mencionados postularon que se trataba del ascenso de una "nueva derecha", ya que presentaba rasgos novedosos y distintivos con las derechas precedentes ${ }^{267}$; para otros, tan solo se reeditaban los patrones que históricamente habían caracterizado a las derechas, favoreciendo una reconcentración del poder de clase ${ }^{268}$.

Hay un núcleo duro del pensamiento, la concepción y las prácticas políticas de la(s) derecha(s) que permanece invariable y define exactamente qué es ella, qué son ellas: la cuestión de la relación igualdad/desigualdad o, si prefiere, la opción por el mantenimiento de la desigualdad ${ }^{269}$.

En consonancia, el autor aclara que no es lo mismo hablar de "nuevas derechas" que preguntarnos "qué hay de nuevo en las derechas". Lo que remite exclusivamente a algunos "nuevos ropajes", es decir, aspectos ocasionales y accesorios que encubren un núcleo permanente u orgánico. Entre las renovadas apariencias de las derechas, los diversos análisis trabajados señalan con fuerza su peculiar formato de representación. El mismo, procura garantizar la centralidad de los miembros directos de las elites empresariales que quieren

\footnotetext{
263 Acosta, Giordano y Soler, "América Latina: nuestra", 2.

264 Hablamos del triunfo de Mauricio Macri en Argentina (2015), sobreponiéndose al candidato del "progresista", y hasta entonces oficialista, Frente para la Victoria; el gobierno provisorio de Michel Temer (2016) en Brasil y la radicalización del distanciamiento respecto del ciclo progresista con el triunfo de Jair Bolsonaro (2018); el retorno de Sebastián Piñera en Chile (2018) tras la gestión “progresista” de Bachelet, y la confirmación de la continuidad de opciones alejadas del "giro a la izquierda" en Perú, Paraguay y Colombia.

265 Acosta y Soler, “América Latina: nuestra". Waldo Ansaldi, "Arregladitas como para ir de boda. Nuevo ropaje para las viejas derechas”, Theomai 35 (2017): 22-5, acceso el 15 de junio de 2020. http://revistatheomai.unq.edu.ar/NUMERO_35/2.\%20Ansaldi.pdf. Giordano, "¿Qué hay de nuevo en las «nuevas derechas»?". Carlos Katz, "La aplicación de Gramsci a Venezuela implicaría hoy asumir decisiones revolucionarias", entrevista en Rebelión, 6 de mayo de 2017. López, América Latina... José Natanson, "Cuando la desigualdad es una elección popular”, Le monde diplomatique 217 (2017): 1-3. Emir Sader, “Hay una nueva derecha en América Latina?". Stefanoni, "La nueva derecha andina”, Anfibia (2012b), acceso el 13 de febrero de 2014, http://www.revistaanfibia.com/cronica/la-nueva-derecha-andina/

266 Nuevamente aquí estaría presente la influencia de Norberto Bobbio para quien las derechas "están convencidas de que las desigualdades son un dato ineliminable". Bobbio, Norberto. Derecha e izquierda..., 15.

${ }^{267}$ Giordano, “¿Qué hay de nuevo en las «nuevas derechas»?”. López, América Latina... Natanson, “Cuando la desigualdad es una elección popular".

268 Ansaldi, "Arregladitas como para ir de boda. Nuevo ropaje para las viejas derechas".

${ }^{269}$ Ansaldi, "Arregladitas como para ir de boda. Nuevo ropaje para las viejas derechas”, 31.
} 
hacer política ${ }^{270}$. En esa línea, no solo los primeros mandatarios mantienen su perfil como hombres de negocios, sino que se rodean de un gabinete de funcionarios-empresarios, algo que en Brasil y Argentina se popularizó como CEOcracia ${ }^{271}$.

Otro rasgo que ha sido señalado como distintivo de las "nuevas derechas" radica en el protagonismo otorgado a las herramientas del marketing político. Con ello, el privilegio de las formas, las imágenes y las estéticas están antes que los contenidos, los debates y los discursos ideologizados. Al respecto el famoso asesor de campañas políticas en la región, Jaime Durán Barba, había anticipado que las elecciones ya no se ganaban llenando la plaza ni recurriendo a discursos cargados, sino más bien apelando a los colores, gestos e imágenes ${ }^{272}$. De manera conjunta se advertía la centralidad de las redes sociales (Facebook, Twitter, Instagram, WhatsApp) para difundir noticias y convocatorias, y crear la sensación de cercanía entre candidatos/gobernantes y la ciudadanía en general $^{273}$.

En vinculación con el rasgo anterior, diversos trabajos han señalado que los gobiernos del "giro a la derecha" manifestaron abiertamente sus pretensiones por consolidar un discurso moderado y consensualista. Esto es, buena parte de las nuevas gestiones se caracterizarían por rechazar la polarización profundizada durante el ciclo previo, y postularían las posibilidades de un pluralismo sin $\operatorname{conflictos}^{274}$. Bajo esa clave de lectura se ha interpretado, por ejemplo, la propuesta del "Quito multicolor" del opositor y entonces alcalde de Quito, Mauricio Rodas ${ }^{275}$; como también la campaña del partido de la oposición boliviana Unidad Nacional bajo el lema "Reconciliación nacional, continuidad e innovación para construir un país para todos"276, e incluso las frecuentes alusiones a la necesidad de "zanjar la grieta kirchnerista" que enarbolaban los funcionarios del macrismo en Argentina ${ }^{277}$.

El reconocimiento de esta tendencia, al menos retórica, despertó varias dudas y controversias, advirtiendo que la creciente conflictividad social en la región colocaba al disenso nuevamente en el espacio público ${ }^{278}$. Al respecto algunos trabajos señalaron que en las respuestas hacia las protestas sociales no faltaron las estrategias de criminalización (vía represión, judicialización o estigmatización); como tampoco las operaciones de

${ }^{270}$ Acosta, Giordano y Soler, "América Latina: nuestra". Ava Gómez, "Desentrañando el gabinete de Iván Duque", CELAG, 2018, acceso el 5 de diciembre de 2018, http://www.celag.org/desentranando-gabinete-ivanduque/. Celso Guanipa, "Paraguay cambia de presidente: ¿cambia algo?", Agencia latinoamericana de información, 16 de agosto de 2018, acceso 24 de agosto de 2018, https://www.alainet.org/es/articulo/194758.

${ }^{271}$ Vale la aclaración que hace Grimson refutando la idea de que con Macri desembarcaron por primera vez los CEO en un gobierno electo en Argentina. El autor recuerda que la empresa agrícola Bunge y Born puso a sus CEO en el Ministerio de Economía de Menem durante la década de los noventa; además, Domingo Cavallo, un economista del establishment más ortodoxo, fue canciller y después ministro de Economía. Alejandro Grimson, ¿Qué es el peronismo? (Buenos Aires: Siglo XXI, 2019). Entonces, podríamos pensar que en los gobiernos del "giro a la derecha" son prácticamente los primeros mandatarios quienes presentan una biografía más cercana al mundo de los negocios que al de la política, sumado a la fuerte presencia de funcionarios con perfil empresario. 272 Jaime Duran y Santiago Nieto. El arte de ganar (Buenos Aires: Debate, 2010).

${ }^{273}$ López, América Latina...

${ }^{274}$ Natanson, "Cuando la desigualdad es una elección popular". López, América Latina... Mouffe, Por un populismo de izquierda...

${ }^{275}$ Ramírez y Coronel, "La política de la «buena onda»".

${ }^{276}$ Fernando Molina, "La oposición boliviana, entre la «política de la fe» y la «política del escepticismo»", Nueva Sociedad 254 (2014): 149-158.

${ }^{277}$ Vommaro, Morresi y Bellotti. Mundo PRO.

${ }^{278}$ Katz, "La aplicación de Gramsci a Venezuela implicaría hoy asumir decisiones revolucionarias". Mora, "Los límites de la restauración neoliberal". Pablo Stefanoni, "Biblia, buey y bala... recargados. Jair Bolsonaro, la ola conservadora en Brasil y América Latina”, Nueva Sociedad 278 (2018): 4-11. 
demonización de las voces disidentes a través de campañas de difamación en los medios de comunicación masiva, el cierre de espacios alternativos de comunicación y el uso de la prisión preventiva en las causas que comprometían a opositores. Ello fue alertado como señal del creciente privilegio de las formas coercitivas de dominación en detrimento de las modalidades persuasivas de hegemonía ${ }^{279}$.

En consecuencia, algunas interpretaciones han dejado vislumbrar la pregunta por las posibilidades de hablar del perfil democrático de las "nuevas derechas". El hecho de que buena parte de estas gestiones haya asumido con voto mayoritario de la población, ameritaría una primera respuesta positiva ${ }^{280}$, tomando distancia de las experiencias del pasado que accedían al poder mediante el fraude o el uso potencial o efectivo de la fuerza. No obstante, rápidamente se objetó que el respeto a la formalidad de las instituciones no resultaba condición exclusiva ni mucho menos suficiente para un régimen democrático ${ }^{281}$; al tiempo que se resabios autoritarios en las modernas derechas ${ }^{282}$. El caso de Brasil ha sido objeto de especiales consideraciones, subrayando que el acceso de Michel Temer al poder (2016-2018) respondió a una operación jurídica, política y mediática que condujo a la destitución de la entonces presidenta Dilma Rousseff vía impeachment ${ }^{283}$. Para algunos analistas dicha experiencia constituía un golpe blando o institucional ya que, si bien no apeló a la fuerza militar para apartar del cargo a una mandataria legal y legítimamente electa, se apoyó en otros poderes del Estado, los medios de comunicación y el empresariado ${ }^{284}$.

La meritocracia también ha sido enunciada como un rasgo distintivo del viraje hacia la derecha y el privilegio de las lógicas empresariales. Para Natanson se ha reemplazado el anhelo de una sociedad más igualitaria (igualdad de resultados) por el objetivo de garantizar condiciones iguales para todos (igualdad de oportunidades) ${ }^{285}$. En ese sentido, se destacan propuestas por garantizar una línea equitativa de largada, para que luego los individuos compitan entre sí y cada uno llegue hasta donde pueda en relación con los esfuerzos individuales - efectuados. El riesgo que ello conlleva radica en la naturalización de las desigualdades, las cuales podrían resolverse en una justa competencia; a la vez que este enfoque privilegia una equívoca comprensión de los problemas sociales colectivos como dificultades individuales ${ }^{286}$.

${ }^{279}$ Katz, "La aplicación de Gramsci a Venezuela implicaría hoy asumir decisiones revolucionarias".

${ }^{280}$ López, América Latina ... Natanson, "Cuando la desigualdad es una elección popular".

${ }^{281}$ Braz, "O golpe nas ilusões democráticas e a ascensão do conservadorismo reacionário”. Martín Granovsky, “¿Derecha democrática?”, Página 12, 2017, acceso el 29 de junio de 2018, https://www.pagina12.com.ar/57262-derecha-democratica

${ }^{282}$ Ezequiel Ipar y Gisela Catanzaro, "Nueva derecha y autoritarismo social”, Revista Anfibia, 2017, acceso el 3 de mayo de 2019, https://revistaanfibia.com/ensayo/nueva-derecha-autoritarismo-social/

${ }^{283}$ Se trata del juicio político aprobado por ambas cámaras legislativas en contra de la entonces presidenta, acusándola de violación a la ley presupuestaria y a la ley de probidad administrativa, y vinculándola con los hechos de corrupción del Lava Jato. El proceso se inició en diciembre de 2015 en la Cámara de Diputados y culminó en agosto de 2016 con la aprobación de su destitución por parte del Senado.

${ }^{284}$ Braz, "O golpe nas ilusões democráticas e a ascensão do conservadorismo reacionário". Tadeu Breda, "Brasil: crónica de un impeachment anunciado. Los colores de un país escindido", Nueva Sociedad 263 (2016): 4-18, http://nuso.org/media/articles/downloads/COY1_Breda_263.pdf

285 Natanson, "Cuando la desigualdad es una elección popular".

${ }^{286}$ Eduardo Castilla, "Meritocracia: el discurso de Cambiemos para borrar a las clases sociales", La Izquierda Diario, septiembre 2017, acceso el 4 de mayo de 2019, https://www.laizquierdadiario.com/Meritocracia-eldiscurso-de-Cambiemos-para-borrar-a-las-clases-sociales. Sol Minoldo, "La meritocracia te la debo", El Gato y la Caja, octubre 2017, acceso el 4 de mayo de 2019, https:/elgatoylacaja.com.ar/la-meritocracia-te-la-debo/ 
Algunas lecturas, entre las que destaca la postura de Emir Sader, agregan que los gobiernos de la nueva oleada de derechas se distinguen por pretender compatibilizar medidas económicas neoliberales con el mantenimiento de políticas sociales implementadas durante la década previa ${ }^{287}$. Bajo esa óptica, se argumentó que los gobiernos del "giro a la derecha" habrían encontrado fuertes obstáculos para romper abiertamente con las políticas de inclusión reforzadas durante el ciclo progresista, Por ello, muchos de los candidatos de las derechas regionales propusieron durante sus campañas que no irían para atrás, sino para adelante, preservando y profundizando los logros sociales ${ }^{288}$. En esa sintonía, Doria Medina en la coyuntura de las elecciones bolivianas de 2014 apelaba a los propósitos del programa de Unidad Nacional que pretendía "una síntesis que recoja lo mejor que hemos hecho hasta ahora y le dé continuidad, que no repita los errores del pasado, y que haga lo que hasta ahora no se ha hecho"289. Al mismo tiempo, Rodas en Ecuador incorporó a su discurso de campaña algunos elementos de la transformación social operada por el correismo (la cuestión social, la titularización de tierras en la periferia, etc. $)^{290}$. Por su parte, al asumir la presidencia de Brasil, Michel Temer afirmó la continuidad de los programas sociales formulados previamente; al tiempo que rechazó la idea de que los nuevos gobiernos debían eliminar lo que hicieron los anteriores y planteó la necesidad de realizar cambios atendiendo a lograr la "eficiencia administrativa", aunque "sin que ninguna de estas reformas altere los derechos adquiridos por los ciudadanos brasileños"291. Incluso, el mismo Jair Bolsonaro (actual presidente de Brasil) manifestó la necesaria continuidad del programa Bolsa Familia e incluyó en sus propuestas de gobierno la creación de un programa de renta mínima para que cada brasilero recibiera el equivalente o más del pago correspondiente a tal asignación ${ }^{292}$. En definitiva, podría considerarse que, a pesar de retomar las doctrinas neoliberales, los gobiernos del "giro a la derecha" han revisado críticamente el neoliberalismo realmente existente durante la década del noventa, a partir de lo cual pretenden "no socavar su autoridad por renunciar a una activa política social hacia los sectores populares"293.

Finalmente, es válido aclarar que la bibliografía en torno al "giro a la derecha" no desconoce la diversidad de situaciones que se presenta al interior de la región y muchos de los textos consultados hablan de "las derechas" en plural ${ }^{294}$. Al respecto, una constatación de suma pertinencia a la hora de profundizar el análisis refiere a que hasta el año 2018, en

\footnotetext{
${ }^{287}$ Sader, “¿Hay una nueva derecha en América Latina?”.

288 Quiroga, María Virginia y Lucía Juncos, "Políticas sociales y nuevos gobiernos en Argentina y Brasil: un balance a partir de los programas Asignación Universal por Hijo y Bolsa Familia”, Polis. Revista Latinoamericana 55 (2020): 172-186.

${ }^{289}$ Molina, "La oposición boliviana, entre la «política de la fe» y la «política del escepticismo»”, 157.

${ }^{290}$ Ramírez y Coronel, "La política de la «buena onda»”, 140.

${ }^{291}$ Temer en Quiroga y Juncos, "Políticas sociales y nuevos gobiernos en Argentina y Brasil: un balance a partir de los programas Asignación Universal por Hijo y Bolsa Familia”, 178.

292 Dimitrius Dantas y Jussara Soares, "Bolsonaro defende 'Bolsa Família’ para todos os brasileiros”, O Globo, 14 de agosto de 2015, acceso el 15 de julio de 2020, https://oglobo.globo.com/brasil/bolsonaro-defende-bolsafamilia-para-todos-os-brasileiros-22977355

${ }^{293}$ Gabriel Vommaro, "La nueva derecha argentina y las paradojas de este tiempo", Horizontes del Sur, n. 2 (junio de 2015): 200, acceso el 17 de marzo de 2019, http://horizontesdelsur.com.ar/wpcontent/uploads/2015/07/24.Vommaro.pdf

${ }^{294}$ Ansaldi, "Arregladitas como para ir de boda. Nuevo ropaje para las viejas derechas". Acosta, Giordano y Soler, "América Latina: nuestra”. Camila Vollenweider y Ava Gómez Daza. Quién es quién. Perfiles políticos de la derecha latinoamericana (Quito: CELAG, 2017).
} 
algunos contextos, la derecha se mantenía en la oposición (Venezuela, Bolivia, Uruguay) ${ }^{295}$; mientras que en otros se desplegaba desde el poder del Estado (Brasil, Colombia, Paraguay, Perú, Argentina y Chile) ${ }^{296}$. Verónica Giordano y Francisco López Segrera coincidieron en que las "derechas" en el gobierno exhibían menos rupturas con las derechas neoliberales tradicionales, que las que mostraban las derechas en la oposición ${ }^{297}$. En tanto que estas últimas daban cuenta, en mayor medida, de un cambio de actitud en relación con el carácter de la democracia (y del Estado). Es decir, a partir de la competencia con el ciclo progresista, estas derechas "ostentan como elemento «nuevo» la bandera de la inclusión, junto a una reivindicación de la democracia política que no es nueva" 298 .

Por su parte, Claudio Katz compartió el diagnóstico de la restauración conservadora de la mano de las derechas, como así también la necesidad de trazar algunas distinciones ${ }^{299}$. Para el autor, por un lado, se mantuvieron los "gobiernos derechistas continuados", que en países como México $^{300}$, Perú o Colombia han aplicado durante muchos años políticas neoliberales. Luego, se han consolidado los "nuevos mandatarios derechistas" que ganaron elecciones, por ejemplo, en Argentina y Panamá. Como tercera variante se emplaza la "derecha que accedió al gobierno por medio de golpes institucionales", dicha modalidad se inició en Honduras en el 2009, continuó en Paraguay en el 2014 y en Brasil en el $2016^{301}$.

Vollenweider y Gómez advierten que las distinciones no atañen solamente a los máximos referentes de las derechas —en muchos casos ocupando la presidencia de sus respectivos países-, sino que pueden hacerse extensivas a la generalidad de sus exponentes $^{302}$. En esa línea, las autoras, se detienen en los sectores juveniles de la "nueva derecha latinoamericana" y diferencian entre aquellos "ahijados de la vieja derecha", las "nuevas caras de la derecha" y los "extrapartidarios". El primer grupo alude a quienes han iniciado su carrera política no solo dentro de los partidos tradicionales, sino en el marco de familias con décadas de presencia en la esfera pública. El segundo conjunto, apunta a figuras novedosas que intentan presentarse como una bocanada de aire fresco en el marco del tradicionalismo. Entretanto, un tercer grupo nuclea a la derecha joven extrapartidaria, citando como los exponentes con mayor visibilidad a los protagonistas de diversas movilizaciones callejeras y convocatorias a través de redes sociales.

Tal como hemos visto, las investigaciones sobre la reconfiguración reciente del mapa político suramericano advierten disparidades entre los países de la región y sostienen debates

295 El caso ecuatoriano merece mención aparte, donde el presidente Lenin Moreno (2017-2021) se había presentado en campaña como continuidad del ciclo progresista protagonizado por Rafael Correa (2006-2017). Una vez en el gobierno, los enfrentamientos públicos entre ambos políticos fueron creciendo hasta derivar en una disputa (y posterior ruptura) por el partido, que desde el 2006 los nucleaba a ambos: Alianza PAIS.

296 Vale advertir que, si prolongamos nuestra mirada en el tiempo, es decir, más allá del 2018, dicha situación muestra notorias variaciones. Por ejemplo, las opciones identificadas con las derechas ya no serían oposición en Bolivia ni en Uruguay; tampoco el oficialismo en Argentina. El caso venezolano se complejiza aún más, si bien Nicolás Maduro (quien reemplazó a Hugo Chávez en la presidencia desde 2013 hasta nuestros días) se mantiene en el poder, la oposición se articuló en torno a la figura de Juan Guaidó (presidente de la Asamblea Nacional) que fue proclamado como "presidente encargado" de Venezuela en un Cabildo abierto en enero de 2019.

${ }^{297}$ Giordano, “¿Qué hay de nuevo en las «nuevas derechas»?”. López, América Latina...

298 Giordano, “QQué hay de nuevo en las «nuevas derechas»?”, 53.

${ }^{299}$ Katz, "La aplicación de Gramsci a Venezuela implicaría hoy asumir decisiones revolucionarias".

${ }^{300} \mathrm{El}$ autor se refiere al gobierno de Enrique Peña Nieto (2012-2018), que fue sucedido por Andrés Manuel López Obrador, identificado con el progresismo.

${ }^{301}$ Nuevamente, mirando más allá del 2018, podríamos sumar el caso de Bolivia en 2019.

${ }^{302}$ Vollenweider y Gómez Daza. Quién es quién... 
acerca de las novedades y persistencias que identifican a las actuales derechas. De esta manera, se destacaron aquí algunos de los rasgos novedosos con que diversos artículos, capítulos de libros y ensayos caracterizaron a las experiencias de la región, colocando mayor o menor énfasis en cada uno de ellos de acuerdo con el caso bajo análisis. Dado que los cambios se van desarrollando en tiempo presente, y de modo vertiginoso, muchos de estos análisis resultan parciales y se desactualizan rápidamente. A su vez, aún no logran consensos sobre las posibilidades de las derechas para construir una nueva hegemonía, como tampoco acerca de las efectivas oportunidades para reditar un nuevo ciclo progresista. No obstante, las pesquisas abordadas significan importantes aportes para intentar comprender el devenir de la región, dando cuenta de su carácter complejo, heterogéneo, dinámico y siempre abierto a la polémica.

\section{Conclusiones}

Las lecturas sistematizadas aquí refieren a los dos giros del mapa político suramericano en el período 2002-2018. En otras palabras, desde el ascenso del ciclo progresista a comienzos del siglo XXI hasta el avance de las "nuevas derechas" en los últimos años. La idea de transición, que adelantábamos en el cierre del primer apartado conforme a las contribuciones de Antonio Gramsci ${ }^{303}$, remite a los cambios de una etapa, proceso o estadio a otro, pero sin desconocer la superposición entre ellos. Es decir, en lo que concierne a nuestro tema de estudio, los ciclos políticos no designan procesos naturales que devienen de un momento a otro ni se reemplazan completamente, sino que se van imbricando y condicionando mutuamente. En ese sentido, y poniendo en consideración las diferentes investigaciones citadas, nos animamos a reconocer algunos rasgos del giro a la derecha en tiempos de progresismo; como también diversas resistencias y búsquedas alternativas en el seno de las nuevas construcciones de derechas.

En cuanto al primer aspecto, en los últimos años del ciclo progresista ya se evidenciaban fuertes roces y cuestionamientos ante la falta (o insuficiencia) de respuestas gubernamentales para temas como la corrupción y la inseguridad, sumado a las críticas por las limitaciones para redefinir un modelo de Estado con gasto público excesivo y alta concentración de poder. Al mismo tiempo, diversos actores colectivos señalaban las contradicciones entre la retórica progresista y la preservación de un sistema económico basado en la extracción de recursos naturales. Ello fue erosionando la legitimidad de los gobiernos del "giro a la izquierda" y consolidó apoyos en torno a discursos más liberales en lo económico, y conservadores en lo político-social. En esa línea, Modonesi había señalado que el giro regresivo de la región no provenía solamente de la llegada al poder de las nuevas gestiones, sino del creciente conservadurismo del ciclo progresista ${ }^{304}$. Este rasgo sería especialmente evidente desde el 2013, a partir del notorio privilegio del capital frente al trabajo y el medio ambiente, como también en el distanciamiento respecto de las organizaciones sociales autónomas.

Con respecto al segundo aspecto que refleja la transición, cabe citar la persistencia de la movilización social frente a los programas de ajuste que implementaron los gobiernos del "giro a la derecha". En ese sentido, destacan las múltiples iniciativas (marchas, concentraciones, acampes, cortes de caminos, huelgas, cacerolazos, entre otras) que han

\footnotetext{
${ }^{303}$ Gramsci, Notas sobre Maquiavelo, sobre la política y sobre el Estado moderno.

304 Modonesi, "Fin de la hegemonía progresista y giro regresivo en América Latina. Una contribución gramsciana al debate sobre el fin de ciclo".
} 
llevado a cabo diversos actores sociales para resistir medidas, reformas o declaraciones de los exponentes de las derechas en el poder que lesionaban algunas de las conquistas otrora alcanzadas. Además, es válido reconocer que esas nuevas gestiones habían triunfado electoralmente en contextos de fuerte polarización política. De modo que los partidos de la oposición conservaron presencia en los parlamentos, en algunas provincias/estados, y procuraron rearmarse de cara a nuevas contiendas. En esa senda, y por citar algunos ejemplos, en las últimas elecciones argentinas (octubre de 2019) Mauricio Macri no pudo retener el triunfo para un segundo mandato, imponiéndose la fórmula del Frente de Todxs con el binomio Alberto Fernández y Cristina Fernández de Kirchner. En Brasil, el presidente Bolsonaro no logra disipar los roces al interior de su gabinete, en un clima de intensa crispación y críticas a raíz del deficiente manejo de la crisis sanitaria provocada por la propagación de la nueva enfermedad COVID-19.

En definitiva, el recorrido por diversos análisis e interpretaciones en torno al mapa político suramericano en el siglo XXI ha permitido identificar ciertos movimientos y rasgos compartidos por la generalidad de los países de la región, así como trayectorias y características específicas para cada contexto nacional. Siguiendo a Giordano, resulta pertinente colocar en primer plano la historicidad de los virajes políticos, emprendiendo abordajes que tomen distancia de conceptualizaciones abstractas o universales y procuren atender a un constante dinamismo ${ }^{305}$.

La pesquisa bibliográfica reveló, además, que mientras el debate sobre la pertinencia de la categoría "izquierda" para calificar a los gobiernos progresistas no permanece saldado, se advierte mayor consenso en relación con el vínculo entre la noción de "derecha" y los nuevos gobiernos conservadores. Las diferencias se profundizan a la hora de sopesar la novedad de estos últimos. Es decir, si bien existe un relativo acuerdo sobre la reconfiguración del mapa político en la coyuntura 2015-2018 y el distanciamiento del ciclo progresista, no habría tantas certezas en cuanto a las continuidades y rupturas que la "nueva derecha" tendría con respecto al neoliberalismo de los años noventa.

La cercanía del contexto analizado, así como su creciente complejidad y dinamismo, han posibilitado hasta el momento balances parciales y provisorios. Como nuevas consideraciones para tener en cuenta, vale la pena mencionar que el 2019 presentó una notoria multiplicidad de protestas y estallidos sociales (especialmente en Chile, Colombia y Ecuador); la destitución de un gobierno democráticamente electo (en Bolivia), y recambios institucionales con alternancia de signo político (en Uruguay y Argentina). Mientras que el 2020 avizora un panorama por demás incierto, haciendo frente a los efectos de la pandemia desatada por la propagación del COVID-19. Sin duda, todo ello retroalimentará futuras investigaciones.

${ }^{305}$ Giordano, Verónica. “¿Qué hay de nuevo en las «nuevas derechas»?”. 


\section{Referencias}

Acosta, Yamandu, Verónica Giordano y Lorena Soler. "América Latina: nuestra". Cuadernos del Pensamiento Crítico Latinoamericano 36 (2016): 1-4.

Alcántara, Manuel. "La escalada de la izquierda. La ubicación ideológica de presidentes y partidos de izquierda en América Latina". Nueva Sociedad 217 (2008): 72-85.

Ansaldi, Waldo. "Arregladitas como para ir de boda. Nuevo ropaje para las viejas derechas". Theomai 35 (2017): 22-5. Acceso el 15 de junio de 2020. http://revistatheomai.unq.edu.ar/NUMERO_35/2.\%20Ansaldi.pdf

Arditti, Benjamín. “El giro a la izquierda en América Latina. ¿Una política post-liberal?”. Latin American Research Review 43, no 3 (2008): 59-81.

Barros, Sebastián. "Espectralidad e inestabilidad institucional. Acerca de la ruptura populista". Ponencia presentada en el VII Congreso Nacional de Ciencia Política, de la Sociedad Argentina de Análisis Político, Córdoba, 2005.

Bobbio, Norberto. Derecha e izquierda, razones y significados de una distinción política. Madrid: Gráfica Internacional, 1997.

Borón, A. y Frei Betto. "Es falso el fin de ciclo progresista". Conferencia en el Centro Cultural IMPA La Fábrica. Buenos Aires, 30 de mayo de 2017.

Braz, Marcelo. "O golpe nas ilusões democráticas e a ascensão do conservadorismo reacionário”. Serv. Soc. 128 (2017): 85-103. http://dx.doi.org/10.1590/0101-6628.095

Breda, Tadeu. "Brasil: crónica de un impeachment anunciado. Los colores de un país escindido". Nueva $\quad$ Sociedad $263 \quad$ (2016): http://nuso.org/media/articles/downloads/COY1_Breda_263.pdf

Burchardt, Hans J. "La crisis actual de América Latina: causas y soluciones”. Nueva Sociedad 267 (2017), 114-128.

Castañeda, Jorge. "Latin America's Left Turn”. Foreign Affairs 85, n. 3 (2006): 28-43.

Castilla, Eduardo. "Meritocracia: el discurso de Cambiemos para borrar a las clases sociales". La Izquierda Diario, septiembre 2017. Acceso el 4 de mayo de 2019. https://www.laizquierdadiario.com/Meritocracia-el-discurso-de-Cambiemos-paraborrar-a-las-clases-sociales

Dantas, Dimitrius y Jussara Soares. "Bolsonaro defende 'Bolsa Família' para todos os brasileiros". O Globo, 14 de agosto de 2015. Acceso el 15 de julio de 2020. https://oglobo.globo.com/brasil/bolsonaro-defende-bolsa-familia-para-todos-osbrasileiros-22977355 
De la Torre, Carlos. "El populismo latinoamericano, entre la democratización y el autoritarismo". Nueva Sociedad (2013) 247: 2-17.

Duran, Jaime y Santiago Nieto. El arte de ganar. Buenos Aires: Debate, 2010.

García, Álvaro. “¿Fin de ciclo progresista o proceso por oleadas revolucionarias?”. Portal digital Pulso de los pueblos, 2017. Acceso el 15 de junio de 2018. http://pulsointernacional.com/fin-de-ciclo-progresista-o-proceso-por-oleadasrevolucionarias-por-alvaro-garcia-linera/

- Las tensiones creativas de la revolución: quinta fase del proceso de cambio. La Paz: Vicepresidencia del Estado Plurinacional de Bolivia, 2011.

Giordano, Verónica. “¿Qué hay de nuevo en las «nuevas derechas»?”. Nueva Sociedad 254 (2014): 46-56.

Gómez, Ava. "Desentrañando el gabinete de Iván Duque”. CELAG, 2018. Acceso el 5 de diciembre de 2018. http://www.celag.org/desentranando-gabinete-ivan-duque/

Gramsci, Antonio. Textos de los cuadernos posteriores a 1931: Antología vol. II. Buenos Aires: Siglo XXI, 1931/2014.

. Notas sobre Maquiavelo, sobre la política y sobre el Estado moderno. Buenos Aires: Nueva Visión, 1962/2003.

Granovsky, Martín. “¿Derecha democrática?”. Página 12, 2017. Acceso el 29 de junio de 2018. https://www.pagina12.com.ar/57262-derecha-democratica

Grimson, Alejandro. ¿Qué es el peronismo? Buenos Aires: Siglo XXI, 2019.

Guanipa, Celso. "Paraguay cambia de presidente: ¿cambia algo?”. Agencia latinoamericana de información, 16 de agosto de 2018. Acceso 24 de agosto de 2018. https://www.alainet.org/es/articulo/194758

Ipar, Ezequiel y Gisela Catanzaro. "Nueva derecha y autoritarismo social". Revista Anfibia, 2017. Acceso el 3 de mayo de 2019. https://revistaanfibia.com/ensayo/nueva-derechaautoritarismo-social/

Katz, Carlos. "La aplicación de Gramsci a Venezuela implicaría hoy asumir decisiones revolucionarias". Entrevista en Rebelión, 6 de mayo de 2017.

Laclau, Ernesto. "La deriva populista y la centroizquierda latinoamericana". Nueva Sociedad 205 (2006): 56-61. 
Lanzaro, Jorge. La tercera ola de las izquierdas latinoamericanas: entre el populismo y la social-democracia. Montevideo: Instituto de Ciencia Política, Universidad de la República, 2007.

Levitsky, Steven y Kenneth Roberts, eds. The Resurgence of the Latin American Left. Baltimore: The Johns Hopkins University Press, 2011.

López, Franciso. América Latina: crisis del posneoliberalismo y ascenso de la nueva derecha. Buenos Aires: ClASCO, 2016.

Machado, Decio y Raúl Zibechi. Cambiar el mundo desde arriba. Los límites del progresismo. Bogotá: Ediciones desde abajo, 2016.

Minoldo, Sol. "La meritocracia te la debo". El Gato y la Caja, octubre 2017. Acceso el 4 de mayo de 2019. https://elgatoylacaja.com.ar/la-meritocracia-te-la-debo/

Modonesi, Massimo. "Revoluciones pasivas en América Latina. Una aproximación gramsciana a la caracterización de los gobiernos progresistas de inicio de siglo". En Horizontes gramscianos. Estudios en torno al pensamiento de Antonio Gramsci, compilado por Massimo Modonesi, 209-236. México: UNAM, 2013.

. "Fin de la hegemonía progresista y giro regresivo en América Latina. Una contribución gramsciana al debate sobre el fin de ciclo". Viento Sur 142 (2015): 23-30.

Molina, Fernando. "La oposición boliviana, entre la «política de la fe» y la «política del escepticismo»". Nueva Sociedad 254 (2014): 149-158.

Mora, Andrés. "Los límites de la restauración neoliberal". Portal digital Pulso de los pueblos, 2017. Acceso el 15 de junio de 2018. http://pulsointernacional.com/los-limites-de-larestauracion-neoliberal-por-andres-mora-ramirez/

Mouffe, Chantal. Por un populismo de izquierda. Buenos Aires: Fondo de Cultura Económica, 2018.

Natanson, José. "Cuando la desigualdad es una elección popular". Le monde diplomatique 217 (2017): 1-3.

Panizza, Fracisco. "Fisuras entre Populismo y Democracia". Stockholm Review of Latin American Sutidies, n. 3 (2008): 81-93.

Paramio, Ludolfo. "Giro a la izquierda y regreso del populismo". Nueva Sociedad 205 (2006): 62-74.

Quiroga, María Virginia. "Debates y recepciones de la perspectiva laclausiana del populismo. Pueblo e instituciones en los discursos populistas latinoamericanos". POSTData, Revista de Reflexión y Análisis Político 19, n. 2 (2014): 377-394. Acceso el 10 de junio de 2020. http://www.revistapostdata.com.ar/2014/11/debates-y-recepciones-de-la- 
perspectiva-laclausiana-del-populismo-pueblo-e-instituciones-en-los-discursospopulistas-latinoamericanos-maria-virginia-quiroga/

Quiroga, María Virginia y Ana Lucía Magrini. "La constitución de un concepto iterativo en América Latina. Tensiones y polémicas en torno al populismo". Revista Fundamentos en Humanidades, año XV, n. ${ }^{\circ}$ II (2014): 27-40. Acceso el 10 de junio de 2020. http://fundamentos.unsl.edu.ar/pdf/articulo-30-27.pdf

Quiroga, María Virginia y Lucía Juncos. "Políticas sociales y nuevos gobiernos en Argentina y Brasil: un balance a partir de los programas Asignación Universal por Hijo y Bolsa Familia". Polis. Revista Latinoamericana 55 (2020): 172-186.

Ramírez, Franklin. "Mucho más que dos izquierdas". Nueva Sociedad, n.o 205 (2006). Acceso 23 de mayo de 2016. http://nuso.org/media/articles/downloads/3379 1.pdf

. “'Posneoliberalismo' y 'neodesarrollismo': ¿Las nuevas coordenadas de acción política de la izquierda latinoamericana?”. Revista La Tendencia 5 (2007): 51-56.

Ramírez, Franklin y Valeria Coronel. "La política de la «buena onda»”. Nueva Sociedad 254 (2014): 136-148.

Retamozo, Martín. "Democracias y populismos en América del Sur: Otra perspectiva. Un comentario a «La democracia en América Latina: la alternativa entre populismo y democracia deliberativa» de Osvaldo Guariglia”. ISEGORÍA. Revista de Filosofía Moral y Política 47 (2012): 615-632.

Rovira, Cristobal. "Toward post-neoliberalism in Latin America". Latin American Research Review 46, n. ${ }^{\circ} 2$ (2011): 225-234.

Sader, Emir. “¿Hay una nueva derecha en América Latina?”. Página 12, 24 de noviembre de 2015. Acceso el 7 de septiembre de 2016, https://www.pagina12.com.ar/diario/contratapa/13-286779-2015-11-24.html . Posneoliberalismo en América Latina. Buenos Aires: CLACSO, 2008.

Soler, Lorena. "Golpe de Estado y derechas en Paraguay". Nueva Sociedad 254 (2014): 7383. Acceso el 5 de noviembre de 2018. http://nuso.org/media/articles/downloads/4070_1.pdf

Stefanoni, Pablo. "Posneoliberalismo cuesta arriba. Los modelos de Venezuela, Bolivia y Ecuador en debate". Nueva Sociedad, 239 (2012a), 51-64.

. "La nueva derecha andina". Anfibia (2012b). Acceso el 13 de febrero de 2014. http://www.revistaanfibia.com/cronica/la-nueva-derecha-andina/

. "Biblia, buey y bala... recargados. Jair Bolsonaro, la ola conservadora en Brasil y América Latina”. Nueva Sociedad 278 (2018): 4-11. 
Stokes, Susan. Globalization and the Left in Latin America. Yale University, 2009. Acceso el 15 de junio 2020. http://citeseerx.ist.psu.edu/viewdoc/download?doi=10.1.1.464.4640\&rep=rep1\&type $=$ pdf

Svampa, Maristella. Cambio de Época. Movimientos sociales y poder político. Buenos Aires: Siglo Veintiuno Editores, 2008.

. Debates latinoamericanos. Indianismo, desarrollo, dependencia, populismo. Buenos Aires: Edhasa, 2016.

. Del cambio de época al fin de ciclo. Buenos Aires: Edhasa, 2017.

Svampa, Maristella y Massimo Modonesi. "Las derivas de los progresismos realmente existentes". La Izquierda Diario, 2016. Acceso 9 de abril de 2017. https://www.laizquierdadiario.com/Las-derivas-de-los-progresismosrealmenteexistente

Vollenweider, Camila y Ava Gómez Daza. Quién es quién. Perfiles políticos de la derecha latinoamericana. Quito: CELAG, 2017.

Vommaro, Gabriel. "La nueva derecha argentina y las paradojas de este tiempo". Horizontes del Sur, n. ${ }^{\circ}$ 2, junio de 2015. Acceso el 17 de marzo de 2019. http://horizontesdelsur.com.ar/wp-content/uploads/2015/07/24.Vommaro.pdf

Vommaro, Gabriel, Sergio Morresi y Alejandro Bellotti. Mundo PRO. Buenos Aires: Planeta, 2015.

Zibechi, Raul. Política y Miseria. Buenos Aires: La Vaca, 2010. 